\title{
El destino y la explotación legitimada en "Tarciso Cantón", de Tatiana Buch
}

\author{
Por: Br. Silvia Solano Rivera', Universidad de Costa Rica \\ Recibido: $\quad 11$ de enero de 2016. \\ Aceptado: $\quad 10$ de mayo de 2016
}

\section{RESUMEN}

En este artículo se analiza el cuento "Tarciso Cantón" (2003) de la mexicana Tatiana Buch (1974 - ). Se parte de la pregunta: ¿cuál es la función del narrador? A partir del análisis de la figura del narrador y su visión de mundo, se concluye que este ofrece una visión sesgada de la población china al servirse de diversos estereotipos para construir la imagen presentada en el relato. Aunado a esto, se examina el papel que la voz narrativa le asigna al destino, para configurarlo como razón de ser de la condición socioeconómica del protagonista. Esto deja de lado el problema de la esclavitud y explotación, tocándolo solo de manera tangencial y proporcionando, simultáneamente, su legitimación al eludir la responsabilidad de los actores humanos en el devenir de Gao. Este trabajo constituye el resultado de investigaciones sobre narrativa breve que en la Universidad de Costa Rica se han llevado a lo largo de las últimas dos décadas.

\section{ABSTRACT \\ FATE AND JUSTIFIED EXPLOITATION IN “TARCISO CANTÓN”, BY TATIANA BUCH}

This paper analyzes the short story "Tarciso Cantón" (2003) by the Mexican author Tatiana Buch (1974 - ). The point of departure is, "which is the role of the narrator?" Based on this analysis of the narrator and her world vision, the conclusion is that such gives a biased vision of the Chinese population because of the use of stereotypes used to construct the image presented in the text. Furthermore, the role of the narrative voice assigned to fate is analyzed in order to set it up as the raison d'etre of the social-economic condition of the protagonist.. This sets aside the problematic issues of slavery and exploitation touching upon them superficially and tangentially, simultaneously providing justification by means of eluding the responsibility of human beings in the transformation of Gao. This paper constitutes the result of research upon brief narration which the Universidad de Costa Rica has been doing for the last two decades.

1 Silvia Solano es Filóloga y egresada de la Maestría en Literatura con énfasis en Literatura Latinoamericana de la Universidad de Costa Rica. Actualmente se encuentra en proceso de redacción de su tesis en esa misma casa de estudios superiores. Contacto: silisori@ gmail.com.
Silvia Solano Rivera. El destino y la explotación legitimada en "Tarciso Cantón", de Tatiana Buch. Revista Comunicación. Año 37, volumen 25, número 1, enero-junio, 2016. Instituto Tecnológico de Costa Rica. ISSN: 0379-3974 / e-ISSN1659-3820.

\section{PALABRAS CLAVE:}

cuento latinoamericano, narrativa mexicana del siglo XXI, Tatiana Buch, estereotipos, chinos, narrador.

\section{KEY WORDS:}

Latin American short story, Mexican narrative of the XXI century, Tatiana Buch, stereotypes, the Chinese, narrator. 


\section{INTRODUCCIÓN}

En este artículo se analiza el cuento "Tarciso Cantón" de la mexicana Tatiana Buch (1974), el cual aparece publicado en la antología Nuevas voces de la narrativa mexicana (2003). A continuación se presenta un análisis de dicho texto literario, cuyo objetivo es explicar la función que desempeña el narrador, partiendo de la pregunta: ¿cuál es la función del narrador en relación con la explotación en el relato de Buch?

Ante tal problema de investigación, surge la hipótesis de que dicha función consiste en legitimar la situación de explotación a través del concepto del destino. Para dar respuesta al problema de investigación, se lleva a cabo una lectura crítica de la manera en que el narrador construye y presenta la realidad de Gao al lector.

En cuanto a la autora y al texto no se ha encontrado ningún artículo académico, únicamente se encontraron líneas favorables en algunos foros de opinión y una brevísima mención en el artículo "Cuentarlo todo: el texto breve como ejercicio de libertad", de Noguerol (2009). La estudiosa apunta que uno de los "rasgos más significativos del cuento reciente" hispanoamericano es "el carácter posnacional o pangeico", es decir, su emancipación "con respecto a cuestiones anteriores demasiado localistas o concretas y dependientes, en general, de los nuevos mapas y estructuras macroeconómicas" (Noguerol, 2009, p. 32). Es en los ejemplos de dicho rasgo donde Noguerol hace referencia al cuento de Buch:

Las tramas se localizan en Ucrania, Bagdad, Australia, los Balcanes o en los países de origen de los autores, considerados desde una perspectiva hostil al centralismo y defensora de la pluralidad. Así, puede protagonizar la historia un trabajador chino en las haciendas henequeneras de Yucatán a principios de siglo, como es el caso del estupendo "Tarciso Cantón" de Tatiana Buch (Noguerol, 2009, p. 32).

El relato "Tarciso Cantón" cuenta la historia de Gao Ken, un chino que huye de su país con el propósito de romper con la tradición familiar de ser jardinero. Llega a México, pasa a Ilamarse Tarciso Cantón e ingresa al círculo económico, primero como peón, luego como vendedor de sorbete y finalmente como dueño de una lavandería, la cual compra al chino José. Alcanza el bienestar socioeconómico, pero por un descuido, José daña un contrato de ropa y el negocio se viene abajo. Deshonrado como Comerciante, Gao no puede pensar en levantar otro negocio. Se corta el pelo, llama al viejo José y es contratado como jardinero en una mansión, oficio del que había huido, pero que el destino le impone.

Es en esta predestinación de Gao y la aparente neutralidad del narrador en lo que centraré mi lectura.

\section{EL SESGO DE LA VOZ NARRATIVA}

Si bien en una primera lectura del relato podría pensarse que nos encontramos ante un narrador neutral el cual se limita a contarnos los hechos' ${ }^{2}$, lo cierto es que dicha neutralidad no existe. En este cuento hay un narrador profundamente sesgado en contra de la población china. Este sesgo se pone de manifiesto al considerar el problema de la esclavitud o la trata de personas como un "viaje" (Buch, 2003, p. 11). Se cosifican las personas y, al mismo tiempo, se les mercantiliza pues el narrador indica que se les "depositaría, finalmente, en la estación de la Mejorada" (Buch, 2003, p. 12), como si se tratase de un bulto de basura o un lote de algún producto importado.

Asimismo, el narrador presenta una visión estereotipada sobre los chinos, la cual comprende varios aspectos expuestos a continuación:

1) Los oficios:

A lo largo del texto los chinos son asociados a determinados oficios, los cuales encarnan estereotipos sobre las funciones que estos "deben" desempeñar. Dado el estereotipo construido de la llamada "raza amarilla", como débiles y proclives a las enfermedades, las labores que realizan son muchas veces feminizadas. En el discurso mexicano de la época narrada (finales del siglo XIX y principios del XX):

2 Recuérdese que la objetividad no existe: siempre en todo media la subjetividad humana, de la cual no podemos abstraernos. 


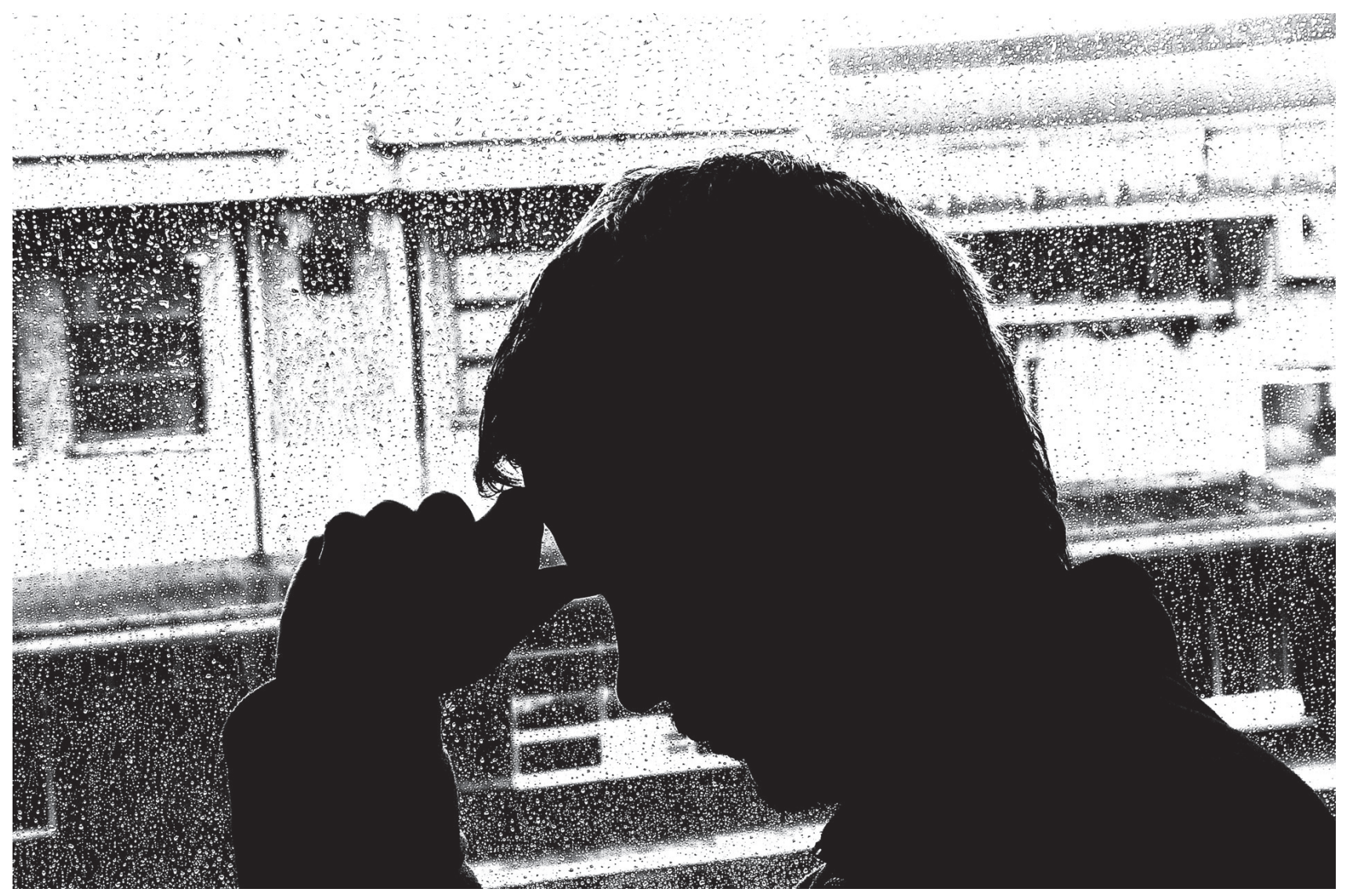

A los chinos se les acusaba de haber desplazado a los trabajadores mexicanos porque estaban dispuestos a realizar cualquier tarea al precio que fuera; habían acaparado labores femeninas como el lavado de ropa y otro servicios, también perjudicaban a los comerciantes mexicanos poniendo negocios que competían de manera desleal y en los que no empleaban a mexicanos (Botton, 2008, p. 481. El destacado es propio).

Además, como señala Treviño:

Eso llevó a decir que 'la parte inicial del pro grama diabólico que los chinos se proponían desarrollar en la República estaba cumplido al invadir las fuentes de actividad en que la cocinera, la criada, la lavandera, el peón, el campesino y el obrero nativos se ganaban la vida; faltaba la segunda parte que consistía en apoderarse del pequeño comercio, hoteles, lavanderías y restaurantes'" (2005, p. 430. El destacado es propio).
Al desempeñar oficios estereotipadamente femeninos, los chinos fueron también feminizados. Ejemplo de este fenómeno se aprecia también en el cuento "Los chinos", de Alfonso Hernández Catá (1885-1940):

En nuestro grupo menudearon los comentarios y las risas: 'Buenos eran los chinos para vender en sus tiendecitas de la ciudad, abanicos, zapatillas, cajitas de laca y jugueticos de papel rizado; excelentes para guisar en sus fonduchos, o para lavar y planchar con primor... iOficios de mujeres, bien! Pero para aguantar el sol sobre las espaldas ocho horas, y agujerear el hierro, ¡hacían falta hombres muy hombres! (Hernández, 2012, p. 280. El destacado es propio).

En el cuento de Buch, la figura del chino está asociada a los oficios domésticos de cocinero: "había sido contratado como ayudante de cocina" (Buch, 2003, p. 11), jardinero, vendedor de sorbete, lavandero, planchador y finalmente encargado de 
la lavandería, todos estos oficios son desempeñados por Gao. Este cambio de las labores revela un paulatino ascenso económico-social que a su vez hace ver al inmigrante chino como arribista, concepción muy arraigada en la época, como se vio en la anterior cita de Botton, y como también lo señala Treviño: "las manifestaciones excesivamente violentas hacia los chinos fueron el resultado de la 'creencia -muy extendida entre los mexicanosde que [...] se habían convertido en un grupo acaudalado y privilegiado'"' (2005, p. 412).

Aunado a estos oficios, se encuentra el de braceros (jornaleros no cualificados que trabajan en el campo), para el cual son traídos los demás chinos que vienen con Gao. Como señala el texto, los chinos eran traídos para desempeñar esta función en las haciendas henequeneras en Yucatán, tal y como lo relata Treviño: "En 1891, los nuevos contingentes se establecieron en Yucatán, Oaxaca y Chiapas, para trabajar en las plantaciones henequeneras y de caña de azúcar" (2005, p. 426). Adicional al estereotipo de braceros o trabajadores de plantaciones, de modo paralelo, se da la imagen de sumisos:

De los chinos, en cambio, se subrayaba la necesidad de fomentar su inmigración para resolver la carencia de braceros requeridos para los trabajos agrícolas de las tierras calientes y templadas del centro y de las costas, así como para la construcción de vías férreas. Uno de los argumentos esgrimidos a 'favor' de la inmigración china era que los 'ojos de gato' se caracterizaban por su laboriosidad, por su sumisión a la autoridad y por su bajo costo como mano de obra (Treviño, 2005, p. 421. El destacado es propio).

Nuevamente, la imagen de sumisión, debilidad y docilidad se emparenta con el estereotipo femenino: "Son dóciles no por virtud sino por su objeción y cobardía" (Botton, 2008, p. 480).

\section{2) Los vicios:}

El narrador presenta una imagen estereotipada de los chinos al asociarlos, en el caso particular del chino José, con vicios como el fumado: "Encontró al chino tumbado en su camastro, fumando una larga pipa" (Buch, 2003, p. 18) y los juegos de azar: "En ocasiones visitaba el casino de sus paisanos. Conservaba todavía cierta viveza para las cartas" (Buch, 2003, p. 20), imagen igualmente difundida en el México de finales de siglo XIX:

En Mazatlán, seis meses después, La Unión de Comerciantes al Menudeo publicó una circular en la que pedía el apoyo del gobierno central para erradicar el mal que representaban los 'viciosos' y 'jugadores' chinos, que, 'hacinados, sudando a chorros y despidiendo olores mefíticos y cacoquinos, semidesnudos [...] fijan sus ojos de felino en la figurita de una baraja o en el número de una diminuta pieza de dominó, en sus pocilgas [...] donde roncan como marranos [...] idiotizados y adormecidos por el opio'" (Treviño, 2005, p. 438).

Incluso se propuso que fueran "multados por 'delinquir contra la salud pública', ya que 'estaba comprobado' que establecían fumaderos de opio". (Treviño, 2005, p. 436).

\section{3) La higiene personal:}

El narrador presenta a un Tarciso que no se preocupa por su higiene personal: "Tan pronto como ahoró un poco de dinero, se pagó un baño. Hacía cuatro meses que su cuerpo no tocaba el agua" (Buch, 2003, p. 17). Esto refuerza el estereotipo de "sucios" que las élites nacionales de los países latinoamericanos, en general ${ }^{3}$, han asignado a los chinos: "En gran medida, fueron construyéndose las imágenes de 'los asiáticos', 'los bárbaros' o de 'los chinos' que son 'perezosos', 'sucios', 'antropófagos', 'insalubres' y un gran etcétera" (Treviño, 2005, p. 418).

3 Desgraciadamente, el estereotipo del chino que hemos ido destacando fue difundido desde Estados Unidos a toda Latinoamérica. Por ejemplo, en la Costa Rica de finales de siglo XIX se creía que eran portadores de "vicios de educación altamente perjudiciales a nuestras costumbres; al mismo tiempo que tienen males de organización o de raza más perjudiciales aún a la salud pública. En lo general son jugadores y ladrones; insubordinados, crueles y vengativos cuando se consideran en mayor número y más fuertes; el abuso de opio y la decidida inclinación al suicidio contribuye a que desprecien la vida haciéndolos peligrosos" (Lizano, 1875, pp. 2-3). Botton señala que durante la depresión de 1870, en Estados Unidos "se acusó a los chinos de robar los empleos de los blancos, de ser 'inasimilables', de 'aferrarse a sus usos y costumbres', de ser 'peligrosos', 'serviles', 'sucios y de asquerosos hábitos"' (2008, p. 479), estereotipos que "fueron heredados por los mexicanos" (2008, p. 479). 
Los chinos son presentados, en tanto inmigrantes, como un otro amenazante por medio de la metáfora de la masa:

Caminaba entre los chinos y cuando alguno de ellos le llamaba la atención le ordenaba, con la punta plateada de su bastón de bambú, que se levantase. El chino obedecía entre murmullos y, si todavía le simpatizaba, siempre con su mismo bastón, don Augusto le señalaba que se apartase de aquella masa humana (Buch, 2003, p. 14. El destacado es propio).

Recuérdese que la metáfora de la masa, forma parte de una serie de metáforas hiperbólicas (inundación, anegación, ola u oleada, invasión, etc.), las cuales buscan realzar las representaciones negativas de los otros como amenazantes para el nosotros (Cf. Van Dijk, 2005). Por otra parte, en relación con la construcción marginal del inmigrante, el texto destaca el carácter de otredad-marginalidad que comparten chinos y mayas (otro externo y otro interno respectivamente), ya que tanto Gao como José logran primero comunicarse con los mayas: "Yo también tengo amigos mayas, con ellos me entendí antes que con los

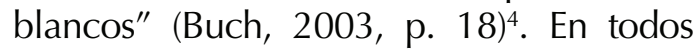
estos aspectos (oficios, vicios, higiene e inmigración), el narrador de "Tarciso Cantón" presenta una imagen estereotipada del chino. Lo único que se podría reconocer como positivo es la imagen de trabajador incansable. Sin embargo, este reconocimiento parte de un discurso

$4 \quad$ Lo cual también nos remite a la hipótesis del origen chino de los mayas, cuyas pruebas son ciertos objetos (monedas) coincidentes en ambas culturas, así como similitudes de las lenguas. Esta hipótesis resulta, a nuestro juicio, absolutamente verosímil, sobre todo si se considera la potencia marítima que fue China para aquella época y los avances cartográficos que tenía en relación con occidente. Asimismo, el aspecto de la lengua también apunta a un carácter marginal compartido, ya que ambas lenguas son ejemplos de lo que Mignolo denomina "lenguas subalternas" (2011, p. 318), las cuales fueron racializadas por la ciencia lingüística que "encontró su inspiración para clasificar las lenguas en el método de las ciencias biológicas" (2011, p. 312), construyendo así un foso entre lenguas occidentales y no occidentales, donde estas últimas están signadas por lo "monstruoso y atrasado" (2011, p. 313). capitalista que únicamente reconoce en ellos su capacidad de producción de capital y no su integridad como seres humanos.

Concluida la lectura del cuento, la historia adquiere un carácter ejemplarizante de lo que le sucede a quienes le dan la espalda a su país y a sus tradiciones por aventurarse a hacer fortuna en otro mundo y en otra cultura. Esto aplica para ambos personajes chinos: Gao y José, quienes experimentan un ascenso socioeconómico lejos de su tierra. El texto detalla el ascenso de Gao, y refiere rápidamente el caso de José "otro chino de nombre José, quien había llegado, varios años atrás, desde la frontera norte del país a trabajar en el henequén y ahora tenía una lavandería" (Buch, 2003, p. 18).

Además, la idea de que ambos personajes solo puedan salir adelante si están relacionados con sus coterráneos pone de manifiesto otro estereotipo: su incapacidad para la asimilación. Tradicionalmente, se ha tachado a los chinos de ser culturalmente muy herméticos, mantener sus costumbres y no dejarse asimilar. Esto resulta paradójico si se piensa que, como señalan los estudios, desde antes de su llegada al territorio ya hay una postura en contra de la inmigración china como mano de obra, la cual se refuerza con la llegada. Es decir, se crea todo un discurso en torno a los chinos como indeseables, contaminantes e insalubres, y luego se pretende que tengan fuertes relaciones con los pobladores nativos y se dejen asimilar, cuando ya se han creado los anticuerpos que prohíben esa relación y que demandan la búsqueda de coterráneos con los cuales relacionarse.

Aunado a todos estos elementos, el texto presenta una parodia del anciano venerable y honorable: José, que en este caso se transforma en la causa del deshonor del negocio y de Gao mismo, quien como símbolo de tal deshonra se corta su trenza. Además de los vicios que se le achacan, se añade la idea del viejo descuidado 
o desconsiderado: por fumar no se da cuenta del daño hecho al negocio y por consiguiente al proyecto de vida de Gao.

\section{EL DESTINO COMO LEGITIMADOR DE LA ESCLAVITUD}

En este apartado se ahondará en un aspecto mencionado de manera tangencial: el contexto narrado. El texto de Buch nos ubica espacialmente con claridad, mientras que la ubicación temporal está dada por la referencia a las henequeneras: "la hacienda henequenera floreció a fines del siglo XIX y principios del XX gracias a la expansión sin precedentes del mercado internacional del henequén, agave que se utiliza para la fabricación de hilos, cuerdas, sogas, tapetes, bolsas, etc." (Peniche, 2011, p. 55). Este desarrollo de las henequeneras se considera "la entrada de Yucatán al capitalismo" (p. 55), lo que implica también una fuerte explotación de los trabajadores hasta llegar al punto de una esclavitud llamada: "esclavitud por deudas",

propia de Yucatán y cuya característica era precisamente la apropiación de las personas de los sirvientes yucatecos no sólo en la relación con sus patrones sino también con comerciantes, el clero y el Estado, es decir, en la relación de (re) producción del sistema (Peniche, 2011, pp. 57-58).

En el México de finales del siglo XIX se discutió "la necesidad de abrir al país a la inmigración" (Botton, 2008, p. 479) y finalmente, por razones prácticas, "se fomentó la entrada de chinos contratados para las haciendas de Yucatán" (Botton, 2008, p. 480). Sin embargo, como los estudiosos se han encargado de demostrar, dichos "contratos" no eran nada distinto de la esclavitud, y contaron con el mutuo acuerdo de China y México:

En 1899 cuando el imperio chino firmó el Tratado de Amistad, Comercio y Navegación. A partir de entonces, las compañías marítimas de navegación, tanto chinas como inglesas, comenzaron la transportación masiva de braceros de manera plenamente legal. Los nuevos inmigrantes 'amarillos', pese a la violencia, el engaño, el secuestro y la seducción usados por las agencias en el enganche de culis, y no obstante las penosas condiciones de su traslado, eran llamados 'trabajadores por contrato' (Treviño, 2005, p. 426).

Además del ambiente de esclavitud y el implícito aval de los gobiernos, en los gobiernos locales se daba una complicidad con los hacendados, tal como relata el estadounidense John Kenneth Turner:

Toda Mérida y todo Yucatán, y aun toda la península, dependen de 50 reyes del henequén. Naturalmente, dominan la política de su Estado y lo hacen en su propio beneficio. Los esclavos son: 8 mil indios yaquis, importados de Sonora; 3 mil chinos y entre 100 y 125 mil indígenas mayas, que antes poseían las tierras que ahora dominan los amos henequeneros (1998, p.11).

El testimonio de Turner se remonta a 1908, y en él pone de manifiesto que efectivamente en las haciendas henequeneras había esclavitud, sin embargo, no era denominada como tal:

Los hacendados yucatecos no llaman esclavitud a su sistema; lo Ilaman servicio forzoso por deudas. 'No nos consideramos dueños de nuestros obreros; consideramos que ellos están en deuda con nosotros. $Y$ no consideramos que los compramos o vendemos, sino que transferimos la deuda y al hombre con ella'. Esta es la forma en que don Enrique Cámara Zavala, presidente de la Cámara Agrícola de Yucatán, explicó la actitud de los reyes de henequén en este asunto. "La esclavitud está contra la ley; no Ilamamos a esto esclavitud", me aseguraron una y otra vez varios hacendados (1998, p. 13).

Del mismo modo, el testimonio de Turner da cuenta de las paupérrimas condiciones en que se encontraban los esclavos, la comida miserable y los fuertes castigos que recibían, así como el proceso de esclavitud de la familia del esclavo "contratado", pues se le exigían una exagerada cantidad de hojas de henequén para que se viera forzado a llevar a su esposa e hijos con él y lograr la cantidad. 
Como se puede ver, el texto remite a un contexto socioeconómico e histórico particular; sin embargo, no se enfoca en la esclavitud o trata de personas y su explotación; sino que pone el énfasis en seguir el programado "destino" de Gao, por encima de los actores humanos explotadores. Esta preponderancia del destino como agente del devenir de Tarciso se ve claramente reforzada por la estructura del relato.

A simple vista, el relato parece encajar en una estructura circular, pero esta solo se presenta a nivel temático, esto es, en el deseo de Gao de romper con la tradición familiar de jardinería: sus antepasados son jardineros; sin éxito, pues él termina trabajando como jardinero. Pero desde el punto de vista espacial, temporal y de las acciones o acontecimientos, el texto contiene otra organización que permite visualizar el carácter ideológico del narrador sobre los hechos.

El eje que estructura el texto es el "viaje" sin regreso de Gao de China a México. Entre los dos puntos se Ileva a cabo una oscilación o vaivén (que simula el movimiento de las olas) por medio del recuerdo, la añoranza y el deseo de honrar a sus ancestros. Este "viaje" espacial también está acentuado por el desplazamiento de Gao en México: de Puerto Salina Cruz, se desplaza en tren a Coatzacoalcos; de Coatzacoalcos navega a Puerto Progreso y de ahí cruza en tren hasta Mérida donde se establece. Una vez ahí, inicia otra movilización, pero esta de carácter socioeconómica: de peón a vendedor de helados y, luego, a dueño de una lavandería que llevará su propio nombre. Así las cosas, desde el punto de vista identitario el personaje también experimenta otro "viaje": pasa de llamarse Gao Ken a ser nombrado Tarciso Cantón. El signo que estructura el relato es la desestabilidad geográfica, espacial, económica, identitaria y cultural del personaje migrante.

Desde la primera línea del cuento, "Gao Ken había querido escapar a su destino" (Buch, 2003, p. 11 ), se proyecta en la figura del destino la responsabilidad de la ruina del personaje, y se desplaza hacia los actores humanos involucrados: los explotadores. Si bien en el texto se hace mención de "las autoridades de migración" (Buch, 2003, p. 12), del contratista "un norteamericano de Nueva Orléans" y del "hacendado" (Buch, 2003, p. 13), no hay evidencia de una perspectiva crítica del problema: se centra en seguir el desenvolvimiento de Gao, a fin de resaltar el cumplimiento del destino señalado: ser jardinero, poniendo de relieve una especie de determinismo. La caída en desgracia de Gao al ser llevado "a la galería donde sus paisanos aguardaban el arribo del buque a tierra firme" (Buch, 2003, p. 11) no se debe, entonces, a los traficantes de personas, sino que es parte de su destino experimentar un descenso de ayudante de cocinero a parte de la "masa humana" y un posterior ascenso como "cargador en el mercado" (Buch, 2003, p. 16), a vendedor de sorbete, lavandero, planchador y finalmente encargado de la lavandería. Luego, vuelve a descender, junto con José, al oficio predestinado para él: la jardinería y hacer ver con más fuerza que nadie escapa a su "destino":

Ese énfasis en el destino programado de Gao hace que se desatienda el circuito de tráfico de personas, pues solamente se mencionan, como ya se dijo, a las autoridades migratorias, el contratista y el hacendado, dejando por fuera a partes indispensables para que la trata se lleve a cabo, en este caso: las jurisdicciones chinas, tanto políticas como migratorias, las jerarquías políticas mexicanas y desde luego, las económicas. Si bien se menciona al intermediario, no ocurre así con el contratista norteamericano ${ }^{5}$, dentro de las autoridades económicas involucradas a los compradores del henequén. Se elude que la "relación sino-mexicana fue llevada a cabo por intereses imperialistas" (Valdés, 1980, p. 827), ya que Estados Unidos fue el principal comprador de henequén, pues "en 1878, la engavilladora Mc. Cormick, adaptó el henequén a su funcionamiento, haciéndolo indispensable para las cosechas de trigo en los EE UU" (Peniche, 2011), "para señalar la importancia del henequén, basta señalar que su principal comprador, Estados Unidos, dependió de la fibra del

5 En el contexto mexicano del emporio henequenero, Estados Unidos estaba implicado como país en el comercio transpacífico, pues antes del tratado de 1899 y luego de él: "El único medio para hacerlo, era el de las embarcaciones pertenecientes en orden de importancia a Inglaterra, Estados Unidos y Francia" (Valdés, 818). 
henequén para encostalar sus cosechas de trigo hasta la invención de las fibras sintéticas a fines de los años 1930" (Peniche, 2011). El problema de la trata de personas parte del sistema capitalista y de la explotación de la mano de obra barata, pues le interesa obtener más beneficios a cambio de menos gastos. En su afán de conseguir mayores ganancias, el sistema capitalista mercantiliza todo lo que esté a su paso, así se trate de seres humanos.

Con respecto a las autoridades mexicanas de migración, se debe destacar el acto de otorgar una nueva identidad a Gao:

También a él las autoridades de migración le entregaron un documento de entrada al país donde venía escrito el nombre que se le había asignado: Tarciso Cantón. Tarciso y los otros trescientos chinos recién bautizados fueron puestos en los vagones de ferrocarril (Buch, 2003, p. 12).

Gómez clasifica lo anterior como un "acto de violencia radical" que "consiste en dar nombre de nuevo, en re-nombrar" (1994, p. 158), ligado al despojo de la identidad.

Visto desde la óptica determinista del destino, el relato presenta en su discurso una re-victimización de las víctimas, ya que quienes pretenden surgir fuera del esquema del tráfico de personas provocan su propia ruina e inevitable inserción dentro del esquema de la esclavitud. Gao "Anhelaba una oportunidad para incorporarse al círculo económico" (Buch, 2003, p. 15), sin embargo su "destino" es exactamente lo contrario; lo relega a una posición de esclavitud. No es casualidad que termine siendo jardinero de "la mansión de los Cámara" (Buch, 2003, p. 24), mismo apellido del hacendado ${ }^{6}$ quien al inicio del relato llega a comprar esclavos. Del mismo modo que Turner señala: "A los esclavos no sólo se les emplea en las plantaciones de henequén, sino también en la ciudad, como sirvientes personales,

6 Y mismo apellido que ya hemos referido en otras citas de Turner, en las que narra cómo Enrique Cámara Zavala, presidente de la Cámara Agrícola de Yucatán, era uno de los reyes del henequén y abanderados del "servicio forzoso por deudas". como obreros, como criados en el hogar o como prostitutas" $^{\prime 1998, ~ p . ~ 16) ~}{ }^{7}$.

\section{CONCLUSIONES}

En "Tarciso Cantón" se encuentra un narrador con una visión sesgada de la población china, ya que se sirve de diversos estereotipos para construir la imagen presentada en el relato. Asimismo, la voz narrativa emplea al "destino" como razón de ser de la condición socioeconómica del protagonista y deja de lado el problema de la esclavitud, pues se aborda tangencialmente, lo cual proporciona, simultáneamente, su legitimación al eludir la responsabilidad de los actores humanos en el devenir de Gao. Si tradicionalmente, el episodio de "la discriminación legalizada de las comunidades chinas entre 1890 y 1930" (Treviño, 2008, p. 672) en México ha sido escamoteado por la historiografía y el Estado mexicanos, se ha procurado "ocultar, negar y normalizar cualquier cuestionamiento sobre las implicaciones raciales o racistas de su desempeño" (Treviño, 2008, p. 687), pareciera que el texto de Buch se inscribe dentro de esta corriente normalizadora, no polemizadora ni cuestionadora al tratar la sinofobia y además tomar partido desde el mismo título, Ilamando al personaje por su nombre impuesto: el narrador se alía así al aparato gubernamental (Migración) que lejos de preocuparse por las condiciones en que los individuos arriban al país, simplemente procura despojarlos de su identidad para su incorporación a las fuerzas laborales sin demora.

De este modo, el texto se convierte en una invitación a indagar sobre la presencia de los chinos en la literatura mexicana y particularmente sobre la esclavitud china en las haciendas henequeneras, lo cual permite reconocer en el texto de Buch un primer paso en cuanto a la mención de un episodio históricamente invisibilizado.

$7 \quad$ En este punto podemos ver que la marginalidad compartida de las culturas no occidentales: china y maya, vuelve a surgir. Pues según los estudios, ambas culturas coinciden en haber sufrido la esclavitud en las haciendas henequeneras de Yucatán. Al terminar el relato, Alfonso el maya (nótese que también ha sido re-nombrado) y Tarciso se encuentran al servicio del hacendado esclavizador. 


\section{REFERENCIAS BIBLIOGRÁFICAS}

Botton, F. (2008). La persecución de los chinos en México. Estudios de Asia y África 2, pp. 477-486.

Buch, T. (2003). Tarciso Cantón. En: Mortiz, J. (Ed.) Nuevas voces de la narrativa mexicana. Antología de cuentos de escritores jóvenes. México D. F.: Editorial Joaquín Mortiz, pp. 11-24.

Gómez, A. (1994). Cómo surge una instancia discursiva: Cristóbal Colón y la invención del 'indio'. Imprévue 1-2, pp. 151-175.

Hernández, A. (2012). Los chinos. En Cuentos. Las Palmas de Gran Canaria: RED Ediciones, pp. 278-282.

Lizano, J. (1875, 19 de julio). Informe sobre inmigración china. La Gaceta Oficial, 19 de julio, pp. 2-3.

Mignolo, W. (2011). 'Una lengua otra': mapas lingüísticos, geografías literarias, panoramas culturales. En: Historias locales / diseños globales. Colonialidad, conocimientos subalternos y pensamiento fronterizo. Madrid: Ediciones Akal, pp. 291-324.

Noguerol, F. (2009). Cuentarlo todo: el texto breve como ejercicio de libertad. En El cuento hispanoamericano contemporáneo. Vivir el cuento. París: Rilma $2 \mathrm{Y}$ Adehl, pp. 31-47.
Peniche, P. (2011, junio). Los secretos de la hacienda henequenera. Legajos, Boletín del archivo general de la nación, 7, pp. 55-64. Recuperado de http://www. agn.gob.mx/menuprincipal/difusion/publicaciones/ pdf/legajos07.pdf

Peniche, P. (2012, junio). Fuentes documentales para la historia de los ferrocarriles en el Archivo General del Estado de Yucatán. Mirada Ferrroviaria, 18, 26-31. Recuperado de http://www.museoferrocarriles.cuadriga.com.mx/sites/default/files/adjuntos/18.pdf

Treviño, J. (2008). Racismo y nación: comunidades imaginadas en México. Estudios sociológicos 26, pp. 669-694.

Treviño, J. (2005). Los 'hijos del cielo' en el infierno: un reporte sobre el racismo hacia las comunidades chinas en México, 1880-1930". Foro Internacional, 3, pp. 409-444.

Turner, J. (1998). México Bárbaro. México D. F.: Editorial Época.

Valdés, V. (1980). México y China: cercanía en la distancia. Estudios de Asia y África, 4, pp. 816-831.

Van Dijk, T. (2005). Nuevo racismo y noticias. Un enfoque discursivo. En Nash, M., Tello, R. y Benach, N. Inmigración, género y espacios urbanos. Los retos de la diversidad. Barcelona: Ediciones Bellaterra, pp. 33-55. 